\title{
Prevalence of ultrasound-detected knee synovial abnormalities in a middle-aged and older general population-the Xiangya Osteoarthritis Study
}

Ting Jiang ${ }^{1,2,3,4 \dagger}$, Tuo Yang ${ }^{3,4,5 \dagger}$, Weiya Zhang ${ }^{3,4}$, Michael Doherty ${ }^{3,4}$, Yuqing Zhang ${ }^{6,7}$, Jie Wei, ${ }^{5,8}$, Aliya Sarmanova ${ }^{9}$, Michelle Hall ${ }^{4,10,11}$, Zidan Yang ${ }^{8}$, Jiatian Li ${ }^{1}$, Gwen S. Fernandes ${ }^{12}$, Abasiama D. Obotiba ${ }^{3,4}$, Sameer A. Gohir ${ }^{11}$, Philip Courtney ${ }^{13}$, Chao Zeng ${ }^{1,8,14^{*}}$ and Guanghua Lei ${ }^{1,8,14^{*}}$ (D)

\begin{abstract}
Background: There is paucity of data on the prevalence of ultrasound-detected synovial abnormalities in the general population, and the relationship between synovial changes and knee pain remains unclear. We examined the prevalence of synovial abnormalities on ultrasound and the relationship of these features with knee pain and radiographic osteoarthritis ( $R O A)$ in a community sample.

Methods: Participants aged 50 years or over were from the Xiangya Osteoarthritis Study, a community-based cohort study. Participants were questioned about chronic knee pain and underwent (1) ultrasonography of both knees to determine presence of synovial hypertrophy ( $\geq 4 \mathrm{~mm}$ ), effusion $(\geq 4 \mathrm{~mm})$, and Power Doppler signal [PDS; yes/no]; and (2) standard radiographs of both knees (tibiofemoral and patellofemoral views) to determine ROA.

Results: There were 3755 participants (mean age 64.4 years; women 57.4\%). The prevalence of synovial hypertrophy, effusion, and PDS were 18.1\% (men 20.2\%; women 16.5\%), 46.6\% (men 49.9\%; women 44.2\%), and 4.9\% (men 4.9\%; women 5.0\%), respectively, and increased with age ( $P$ for trend $<0.05$ ). Synovial abnormalities were associated with knee pain, with adjusted odds ratios (aORs) of 2.39 (95\% confidence interval [Cl] 2.00-2.86) for synovial hypertrophy, $1.58(95 \% \mathrm{Cl} 1.39-1.80)$ for effusion, and $4.36(95 \% \mathrm{Cl} 3.09-6.17)$ for PDS. Similar associations with ROA were observed, the corresponding aORs being 4.03 (95\% $\mathrm{Cl} 3.38-4.82)$, 2.01 (95\% $\mathrm{Cl} 1.76-2.29)$, and 6.49 (95\% Cl 4.51-9.35), respectively. The associations between synovial hypertrophy and effusion with knee pain were more pronounced among knees with ROA than those without ROA, and the corresponding $P$ for interaction were 0.004 and 0.067 , respectively.
\end{abstract}

Conclusions: Knee synovial hypertrophy and effusion are more common and increase with age, affecting men more than women. All three ultrasound-detected synovial abnormalities associate both with knee pain and ROA, and knee synovial hypertrophy or effusion and ROA may interact to increase the risk of knee pain.

Keywords: Synovial abnormalities, Knee, Ultrasonography, General population

\footnotetext{
*Correspondence: zengchao@csu.edu.cn; lei_guanghua@csu.edu.cn

${ }^{\dagger}$ Ting Jiang and Tuo Yang contributed equally to this work.

'Department of Orthopaedics, Xiangya Hospital, Central South University, 87

Xiangya Road, Changsha 410008, Hunan, China

Full list of author information is available at the end of the article
}

C C The Author(s). 2021 Open Access This article is licensed under a Creative Commons Attribution 4.0 International License, which permits use, sharing, adaptation, distribution and reproduction in any medium or format, as long as you give appropriate credit to the original author(s) and the source, provide a link to the Creative Commons licence, and indicate if changes were made. The images or other third party material in this article are included in the article's Creative Commons licence, unless indicated otherwise in a credit line to the material. If material is not included in the article's Creative Commons licence and your intended use is not permitted by statutory regulation or exceeds the permitted use, you will need to obtain permission directly from the copyright holder. To view a copy of this licence, visit http://creativecommons.org/licenses/by/4.0/ The Creative Commons Public Domain Dedication waiver (http://creativecommons.org/publicdomain/zero/1.0/) applies to the data made available in this article, unless otherwise stated in a credit line to the data. 


\section{Background}

Knee pain is highly prevalent in the middle-aged and older population, with a prevalence ranging from 25.0 to $47.1 \%$ [1-3]. Chronic knee pain decreases lower limb strength [4], limits daily activities [5], reduces quality of life [6], and associates with increased all-cause mortality [7]. Although commonly associated with knee osteoarthritis (OA), the pathogenesis of this common disorder has not been fully elucidated, though synovial pathology is thought to play an important role and is, therefore, a common treatment target $[8,9]$. Magnetic resonance imaging (MRI) especially contrast-enhanced MRI (CE-MRI) has been used to assess knee synovial abnormalities $[8,10,11]$. However, owing to its limited availability, long examination time, high associated costs, possible allergic reactions, and potential risk of contrast-induced nephrogenic systemic fibrosis [12], it is unfeasible to routinely perform MRI or CE-MRI as an initial and subsequently repeated test, especially for multiple joint assessments.

Ultrasonography is an accurate, widely available, inexpensive and noninvasive imaging modality that has been used increasingly for evaluating synovial abnormalities $[13,14]$. Without requirement of contrast agents to visualize synovium, ultrasound offers more accurate assessment of synovial abnormalities than conventional clinical examination [15] and can be as sensitive and specific as CE-MRI [16]. In addition, Power Doppler (PD) ultrasound modes provide a unique opportunity to detect indirect signs of increased vascularization, which reflects with high sensitivity joint inflammatory activity [17]. However, there are few epidemiological studies that describe the prevalence of knee synovial abnormalities on ultrasound or examine the relation of these features to knee symptoms and radiographic osteoarthritis (ROA) in the general population [18-22]. Lack of such data makes it difficult to interpret the diagnostic information provided by ultrasound in people who have symptoms that are possibly attributable to synovial abnormalities. In particular, over half of people with knee pain have no ROA [23, 24], and in clinical practice, it is unclear how to investigate and manage such people and whether additional imaging with ultrasound would be of clinical value.

To help fill this gap, we conducted a population-based study to determine the prevalence of ultrasound-detected synovial abnormalities (synovial hypertrophy, effusion, and PD signal [PDS]) of knee joints and examined their associations with knee pain and ROA among middle-aged and older men and women who were representative of the general population living at Longshan County, China.

\section{Methods}

Study design and population

Participants in this cross-sectional study were from the Xiangya Osteoarthritis Study (XO Study), an ongoing community-based longitudinal study of the natural history of OA and its risk factors in Longshan County, Hunan Province, China $[25,26]$. Based on a multistage, stratified random sampling of villages, all residents aged 50 years or older from 25 randomly selected villages were invited. This study was approved by the Ethics Committee of Xiangya Hospital, Central South University (201510506) and registered on ClinicalTrials.gov (NCT04033757). Written informed consent was obtained from all participants.

Among 4742 randomly selected individuals, 4080 (86.04\%) consented to participate at baseline. The XO Study consists of 3 sub-cohorts. Sub-cohort 1 was recruited in 2015 when 1469 individuals completed their interviews and clinical examinations [25]. Of these 1207 and 1181 participants attended the Year 1 (Year 2016) and Year 2 (Year 2017) follow-ups, respectively. Subcohorts $2(n=1271)$ and $3(n=1340)$ were recruited in 2018 and 2019, respectively. Bilateral knee ultrasound was taken for each Sub-cohort 1 participant in 2017 (i.e., the second year follow-up visit), and for Sub-cohort 2 participants in 2018 and Sub-cohort 3 in 2019 (i.e., both baseline examinations) (Supplemental Figure 1). Among 3792 participants who attended for assessment, 37 (1.0\%) were excluded from the current analyses because of not undergoing ultrasound examination $(n=32)$, previous knee replacement surgery $(n=1)$, current severe knee injury $(n=1)$, artificial limb $(n=1)$, or severe lower limb deformity $(n=2)$. Thus, the final sample comprised 3755 individuals.

\section{Assessment of ultrasound}

One trained sonographer (T), over 10 years' experience in musculoskeletal ultrasonography) performed all ultrasound examinations using a Philips CX30 ultrasound machine with a $4-12-\mathrm{MHz}$ linear transducer. A pulse repetition frequency of $400 \mathrm{~Hz}$ was used for PD examination, the gain being adjusted until the background signal was removed. The sonographer was blinded to the participant's knee pain status and radiographic score.

Both knees were assessed with the participant supine and the knee in $30^{\circ}$ flexion. The suprapatellar bursa was scanned according to the Outcome Measures in Rheumatology (OMERACT) atlas [14]. Synovial hypertrophy and effusion were assessed using OMERACT-7 definitions [27] (Supplemental Figure 2). The maximal synovial thickness and effusion depth were measured in millimeters using the longitudinal axis. Presence of synovial hypertrophy was defined as synovial thickness $\geq 4$ $\mathrm{mm}$, and presence of joint effusion was defined as depth of effusion $\geq 4 \mathrm{~mm}$ according to the European League Against Rheumatism (EULAR) study [28]. PDS observed in the synovial membrane in both longitudinal and transverse planes was scored using a semi-quantitative 
grading system, from 0 to $3(0=$ absent, $1=$ mild, $2=$ moderate, 3 = marked or severe) [29] (Supplemental Figure 3). Participants were defined as having synovial hypertrophy, effusion, or PDS if these features were present in either knee.

To assess intra-observer reliability of the ultrasound measures, 30 grey scale and 30 PD stored ultrasound images from 55 participants with different severity of synovial abnormalities were selected, and then re-read by the same assessor (TJ) at a minimum of 12 weeks after acquisition of ultrasound, blind of the original scores. For inter-observer reliability, two assessors (TJ, MH) independently assessed the same 30 grey scale and $30 \mathrm{PD}$ ultrasound images. Weighted kappa statistic was used for semi-quantitative data and intra-class correlation coefficient (ICC) was used for continuous data.

\section{Assessment of pain}

All the visit participants were asked about knee symptoms with the question: "During the past 12 months, have you had pain, aching, or stiffness in or around your right or left knee on most days for at least 1 month?" A positive response was considered to indicate presence of chronic knee pain. The severity of current knee pain was assessed by the Western Ontario and McMaster Universities Osteoarthritis Index (WOMAC), with a 5-point pain scale from 0 to 4 [30]. We divided pain severity into three categories: no pain (WOMAC score 0 on all five pain questions), mild to moderate pain (WOMAC score $1 / 2$ on any of the pain questions), and severe to extreme pain (WOMAC score $3 / 4$ on any of the pain questions) [31].

\section{Assessment of ROA}

Participants underwent a bilateral weight-bearing posterior-anterior semi-flexed tibiofemoral (TF) view radiograph, as well as skyline patellofemoral (PF) views with the person in a supine position and the knee flexed to $45^{\circ}$ using a wedge for accuracy. Radiographs of the TF and PF joints were graded using Kellgren-Lawrence (KL) grades (range 0-4) (Supplemental Figure 4 and 5). Knee ROA was defined as presence of a KL grade $\geq 2$ in any TF or PF joint of each knee.

A single researcher (primary reader, TY, orthopedic surgeon) scored all knee films. Prior to the assessment, one senior bone-and-joint radiologist (Piran Aliabadi) scored twenty films which were selected from the XO Study. The primary reader reviewed the twenty prescored films to calibrate his reading with the senior radiologist's reading. Preliminary reading of batches of randomly selected films continued until the primary reader reached a high level of intra- and inter-rater agreement. With each new batch of films $(n=50)$, we commingled two films from the pre-scored films by the senior radiologist (Piran Aliabadi), and five previously read radiographs by the primary reader himself to test the reliability.

\section{Assessment of covariates}

Demographic characteristics were collected face-to-face by trained health professional interviewers using standard questionnaires. Age, sex, smoking, alcohol drinking, education, and knee injury history were recorded. Height and weight were measured, and body mass index (BMI) was calculated as weight $(\mathrm{kg})$ divided by square of height $\left(\mathrm{m}^{2}\right)$. We grouped BMI into three categories: normal (BMI $<25 \mathrm{~kg} / \mathrm{m}^{2}$ ), overweight (BMI $25-29.9 \mathrm{~kg} / \mathrm{m}^{2}$ ), and obesity (BMI $\geq 30 \mathrm{~kg} / \mathrm{m}^{2}$ ).

\section{Statistical analysis}

Continuous variables were expressed as mean \pm standard deviation (SD), while categorical variables were expressed as percentage. We calculated the sex- and age-specific (50-59, 60-69, $\geq 70$ years) prevalence of each ultrasound-detected synovial feature as the number of cases was divided by the total number of participants in each stratum separately and its $95 \%$ confidence intervals [32]. We examined the associations of each knee synovial feature with knee pain and ROA. The odds ratio $(\mathrm{OR})$ and related $95 \%$ confidence interval (CI) were generated from the Generalized Estimating Equations using the PROC GENMOD procedure in SAS with logit links, with adjustment for potential confounders (age, sex, BMI $\left[<25, \geq 25 \mathrm{~kg} / \mathrm{m}^{2}\right]$, smoking status, alcohol consumption, education level, and knee injury history).

As pain is a subjective experience and unique to each person, we further conducted a within-person kneematched analysis by examining the relationship of knee synovial abnormalities to knee pain among participants who had discordant pain status among two knees [31]. This approach eliminated person-level confounders [31]. Participants with chronic knee pain in one knee but not the other were eligible for the analysis. In addition, participants with bilateral knee pain who reported discordance between knees in categories of pain severity were selected to examine the relationship between synovial abnormalities and knee pain severity. Conditional logistic regression was used to examine associations of synovial abnormalities with each pain measurement because of the matched nature of the data.

To assess whether the association between each synovial abnormality and prevalent knee pain varied according to knee ROA status, we grouped knees into four categories according to the presence or absence of kneespecific synovial abnormalities and ROA and examined relation of each category to knee pain. Using interaction analyses, we tested whether the association between each 
synovial abnormalities and knee pain was modified by knee ROA status.

All $P$ values were 2 -sided and $P<0.05$ was considered significant. All statistical analyses were conducted using SAS V.9.4 (SAS Institute, Cary, NC, USA).

\section{Results}

Of the 3755 participants included in this analysis, $57.4 \%$ were women, the mean age was 64.4 (SD 9.2) years, and the average BMI was $24.0 \mathrm{~kg} / \mathrm{m}^{2}$ (Table 1). Prevalence of chronic knee pain was $33.2 \%$, and prevalence of knee ROA (TF/PF joint OA) was $37.0 \%$. The intra- and interrater reliability were excellent for synovial hypertrophy (range of ICCs 0.94-0.99), effusion (range of ICCs 0.960.98), PDS (range of weighted Kappa statistics 0.82-

Table 1 Characteristics of the study sample

\begin{tabular}{|c|c|}
\hline & Total $(n=3755)$ \\
\hline Women, n (\%) & $2157(57.4 \%)$ \\
\hline \multicolumn{2}{|l|}{ Age, years (\%) } \\
\hline $50-59$ & 33.7 \\
\hline $60-69$ & 36.1 \\
\hline$\geq 70$ & 30.2 \\
\hline Height, cm (mean \pm SD) & $151.1 \pm 8.0$ \\
\hline Weight, kg (mean \pm SD) & $54.8 \pm 9.9$ \\
\hline BMI, $\mathrm{kg} / \mathrm{m}^{2}($ mean $\pm \mathrm{SD})$ & $24.0 \pm 3.6$ \\
\hline Overweight, n (\%) ${ }^{a}$ & 1099 (30.4\%) \\
\hline Obesity, n (\%) & $215(5.9 \%)$ \\
\hline \multicolumn{2}{|l|}{ Smoking status (\%) } \\
\hline Non-smoker & 65.4 \\
\hline Ex-smoker & 4.4 \\
\hline Current smoker & 30.2 \\
\hline \multicolumn{2}{|l|}{ Alcohol drinking (\%) } \\
\hline Non-drinker & 53.8 \\
\hline Ex-drinker & 11.5 \\
\hline Current drinker & 34.7 \\
\hline Education (educated, \%) ${ }^{c}$ & 67.2 \\
\hline Knee injury history (\%) ${ }^{d}$ & 3.4 \\
\hline Chronic knee pain (\%) ${ }^{e}$ & 33.2 \\
\hline Knee radiographic OA (\%) ${ }^{f}$ & 37.0 \\
\hline
\end{tabular}

$n$ number, $S D$ standard deviation, $B M I$ body mass index, $O A$ osteoarthritis ${ }^{a}$ Overweight was defined as a BMI of 25 to $29.9 \mathrm{~kg} / \mathrm{m}^{2}$. In total, 3621 participants had complete anthropometric measurements (weight and height) ${ }^{b}$ Obesity was defined as a BMI of $\geq 30 \mathrm{~kg} / \mathrm{m}^{2}$ 'Educated was defined as primary school or above

${ }^{d}$ Knee injury history was defined as history of knee injury severely restricting walking for at least 1 week

${ }^{e}$ Chronic knee pain was based on a self-report of whether participant had pain, aching, or stiffness in or around their right or left knee on most days for at least 1 month within the past year

${ }^{f}$ Knee radiographic OA was confirmed if at least one knee (tibiofemoral or patellofemoral joint) was rated as Kellgren and Lawrence grade $\geq 2$
1.00), and KL grade (range of weighted Kappa statistics 0.76-0.91) (Supplemental Table 1).

The prevalence of synovial hypertrophy, effusion, and PDS were 18.1\% (men 20.2\%; women 16.5\%), 46.6\% (men 49.9\%; women 44.2\%), and 4.9\% (men 4.9\%; women 5.0\%), respectively. As shown in Fig. 1 and Supplemental Table 2, the prevalence of each specific synovial feature increased with age $(P$ for trend $<0.05)$. Men had higher prevalence of synovial hypertrophy and effusion than women $(P<0.01)$, but there was no sex difference in the prevalence of PDS.

The associations of synovial abnormalities with knee pain severity are shown in Table 2. Compared with knees without synovial hypertrophy, crude ORs of mild to moderate pain versus no pain was 1.81 (95\%CI $1.51-$ 2.16) and severe to extreme pain versus no pain was 4.04 (95\%CI 3.18-5.13), and the results persisted after adjusting for potential confounders. The unadjusted ORs of knee pain were 2.54 (95\%CI 2.15-2.99) for synovial hypertrophy, $1.61(95 \% \mathrm{CI} 1.43-1.82)$ for effusion, and 4.98 (95\%CI 3.63-6.82) for PDS, respectively (Supplemental Table 3). Results from within-person kneematched analyses of synovial abnormalities among participants with discordant knee pain status were similar (Supplemental Table 4).

As shown in Table 3, compared with knees without synovial hypertrophy, knees with hypertrophy had 3.04 (95\%CI 2.52-3.67), 6.20 (95\%CI 4.90-7.83), and 10.22 (95\%CI 7.40-14.11) times higher odds of KL grades 2, 3, and 4, respectively. Findings for the relationship between effusion and PDS with severity of knee ROA were similar. These relationships remained after adjustment for confounders. The crude ORs of knee ROA were 4.27 (95\%CI 3.63-5.02) for synovial hypertrophy, 2.01 (95\%CI 1.79-2.26) for effusion, and 7.97 (95\%CI 5.72-11.08) for PDS (Supplemental Table 5).

According to Table 4, the relation to knee pain was stronger among knees with both synovial hypertrophy and ROA (crude OR $=5.51,95 \% \mathrm{CI} 4.27-7.11$ ) than knees with ROA alone (crude OR $=2.45$, 95\%CI $2.10-$ 2.87 ) or knees with synovial hypertrophy alone (crude $\mathrm{OR}=1.46,95 \%$ CI $1.10-1.93)(P$ for interaction $=0.004)$. A similar pattern was also observed when association between effusion and knee pain was examined, but not between PDS and knee pain. Adjusting for potential confounders (Table 4) and conducting a within-person knee-matched analysis among participants with discordant knee pain status (Supplemental Table 6) did not change the results substantially.

\section{Discussion}

In this large general population-based study, nearly half the participants $(46.6 \%)$ had knee effusion on ultrasound and synovial hypertrophy and PDS were found in $18.1 \%$ 


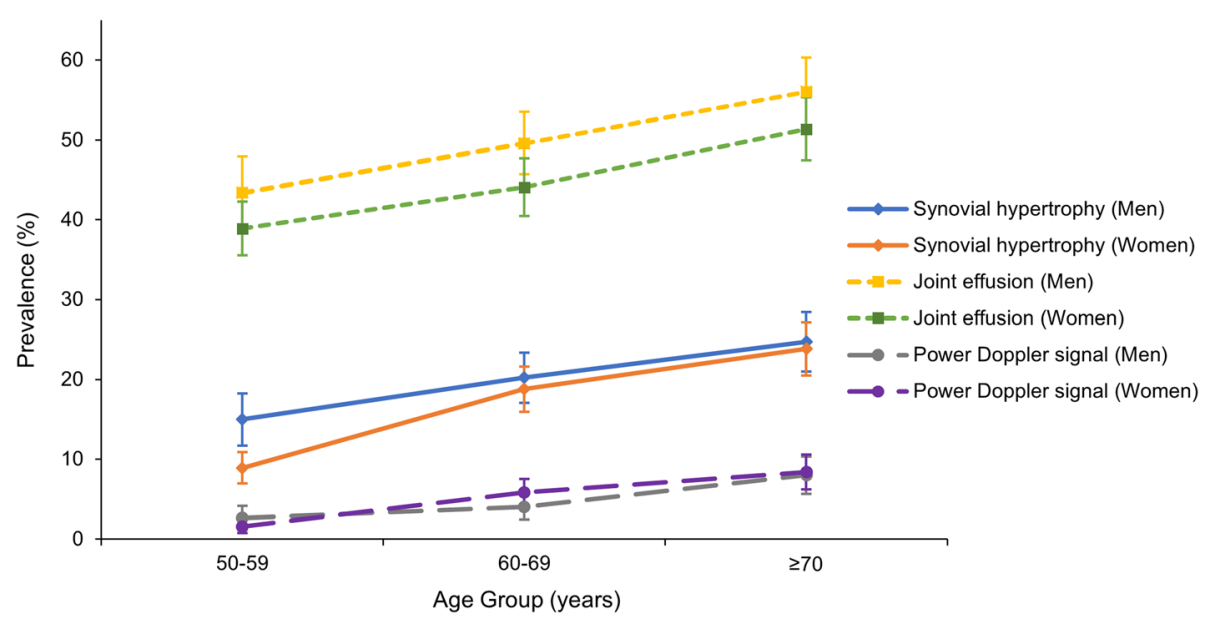

Fig. 1 Prevalence of knee synovial abnormalities on ultrasound among middle-aged and elderly persons, according to age group and sex. The error bars denote $95 \%$ confidence intervals

and $4.9 \%$ of participants, respectively. The prevalence of synovial abnormalities increased with age, and men appeared to have higher prevalence of synovial hypertrophy and effusion, but not PDS, than women. Synovial abnormalities associated with both knee pain and ROA. The association with knee pain was independent from ROA, and the presence of synovial abnormality (synovial hypertrophy or joint effusion) and ROA interacted to increase the risk of knee pain.
Few studies have reported the prevalence of ultrasound-detected synovial abnormalities in community-based samples who were not selected on the basis of knee problems [19-22]. In Newcastle in the UK, effusion was detected in $24 \%$ and $20 \%$ of right and left knees, respectively, among 311 participants aged 61 to 63 years [19]. In the Italian Bruneck population-based cohort, the prevalence of synovial hypertrophy, effusion, and PDS were $43.9 \%, 60.4 \%$, and $22.6 \%$, respectively,

Table 2 Association of knee synovial abnormalities on ultrasound and knee pain severity

\begin{tabular}{|c|c|c|c|}
\hline \multirow[t]{2}{*}{ Synovial abnormalities } & \multicolumn{3}{|c|}{ Knee pain severity ${ }^{b}$} \\
\hline & No pain & Mild to moderate pain & Severe to extreme pain \\
\hline \multicolumn{4}{|l|}{ Synovial hypertrophy } \\
\hline No, n (\%) & $4145(63.6)$ & 1937 (29.7) & $439(6.7)$ \\
\hline Yes, n (\%) & $360(44.0)$ & $304(37.2)$ & $154(18.8)$ \\
\hline Crude OR (95\% Cl) & 1.00 (reference) & $1.81(1.51,2.16)$ & $4.04(3.18,5.13)$ \\
\hline Adjusted OR $(95 \% \mathrm{Cl})^{\mathrm{a}}$ & 1.00 (reference) & $1.79(1.48,2.15)$ & $3.67(2.82,4.78)$ \\
\hline \multicolumn{4}{|l|}{ Joint effusion } \\
\hline No, n (\%) & $3192(64.6)$ & $1426(28.9)$ & $323(6.5)$ \\
\hline Yes, n (\%) & $1313(54.7)$ & $815(34.0)$ & $270(11.3)$ \\
\hline Crude OR (95\% Cl) & 1.00 (reference) & $1.39(1.23,1.57)$ & $2.03(1.66,2.48)$ \\
\hline Adjusted OR $(95 \% \mathrm{Cl})^{\mathrm{a}}$ & 1.00 (reference) & $1.41(1.24,1.60)$ & $1.93(1.55,2.39)$ \\
\hline \multicolumn{4}{|l|}{ Power Doppler signal } \\
\hline No, n (\%) & $4446(62.4)$ & $2156(30.2)$ & $530(7.4)$ \\
\hline Yes, n (\%) & $59(28.5)$ & $85(41.1)$ & $63(30.4)$ \\
\hline Crude OR $(95 \% \mathrm{Cl})$ & 1.00 (reference) & $2.97(2.09,4.23)$ & $8.96(5.99,13.39)$ \\
\hline Adjusted OR $(95 \% \mathrm{Cl})^{\mathrm{a}}$ & 1.00 (reference) & $2.77(1.92,4.01)$ & $7.19(4.50,11.48)$ \\
\hline
\end{tabular}

$n$ number, $O R$ odds ratio, $\mathrm{Cl}$ confidence interval

${ }^{a}$ Adjusted for age, sex, BMI, smoking status, alcohol consumption, education, and knee injury history

${ }^{b}$ Severity of knee pain was categorized into severe to extreme pain (WOMAC score of 3 or 4 on any of the five pain questions), mild to moderate pain (WOMAC

score of 1 or 2 on any of the five pain questions), and no pain (WOMAC score of 0 on all five pain questions) 
Table 3 Association of knee synovial abnormalities on ultrasound and Kellgren-Lawrence grades

\begin{tabular}{|c|c|c|c|c|}
\hline \multirow[t]{2}{*}{ Synovial abnormalities } & \multicolumn{4}{|c|}{ Kellgren-Lawrence grades } \\
\hline & $<2$ & 2 & 3 & 4 \\
\hline \multicolumn{5}{|l|}{ Synovial hypertrophy } \\
\hline No, n (\%) & $4979(74.9)$ & $1179(17.7)$ & $363(5.5)$ & $125(1.9)$ \\
\hline Yes, n (\%) & $343(41.2)$ & $247(29.6)$ & $155(18.6)$ & $88(10.6)$ \\
\hline Crude OR (95\% Cl) & 1.00 (reference) & $3.04(2.52,3.67)$ & $6.20(4.90,7.83)$ & $10.22(7.40,14.11)$ \\
\hline Adjusted OR $(95 \% \mathrm{Cl})^{\mathrm{a}}$ & 1.00 (reference) & $2.98(2.43,3.65)$ & $6.07(4.69,7.86)$ & $9.69(6.82,13.76)$ \\
\hline \multicolumn{5}{|l|}{ Joint effusion } \\
\hline No, n (\%) & $3829(76.0)$ & $855(17.0)$ & $261(5.2)$ & $94(1.8)$ \\
\hline Yes, n (\%) & $1493(61.2)$ & $571(23.4)$ & $257(10.5)$ & $119(4.9)$ \\
\hline Crude OR (95\% Cl) & 1.00 (reference) & $1.71(1.50,1.96)$ & $2.53(2.08,3.07)$ & $3.25(2.36,4.46)$ \\
\hline Adjusted OR $(95 \% \mathrm{Cl})^{\mathrm{a}}$ & 1.00 (reference) & $1.75(1.51,2.03)$ & $2.53(2.04,3.14)$ & $3.15(2.23,4.44)$ \\
\hline \multicolumn{5}{|l|}{ Power Doppler signal } \\
\hline No, n (\%) & $5269(72.5)$ & $1372(18.9)$ & $456(6.3)$ & $169(2.3)$ \\
\hline Yes, n (\%) & $53(24.9)$ & $54(25.3)$ & $62(29.1)$ & $44(20.7)$ \\
\hline Crude OR $(95 \% \mathrm{Cl})^{\mathrm{a}}$ & 1.00 (reference) & $3.91(2.64,5.80)$ & $13.52(9.07,20.15)$ & $25.88(16.34,40.99)$ \\
\hline Adjusted OR $(95 \% \mathrm{Cl})^{\mathrm{a}}$ & 1.00 (reference) & $3.46(2.27,5.29)$ & $11.64(7.45,18.19)$ & $20.93(12.30,35.61)$ \\
\hline
\end{tabular}

$n$ number, $O R$ odds ratio, $\mathrm{Cl}$ confidence interval

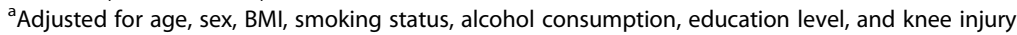

among 433 survivors in the fourth follow-up (927 participants at baseline) [20]. In the Nottingham Knee Pain and Related Health in the Community Study in the UK, the prevalence was $23.9 \%$ for synovial hypertrophy, 50.9\% for effusion, and $0.7 \%$ for PDS in 163 participants with no knee pain or ROA [21]. In the Johnston County Osteoarthritis Project, evidence of effusion/synovitis on ultrasound was found in $80.3 \%$ of 396 knees of 203 participants using a semi-quantitative assessment atlas [22]. The prevalence of synovial abnormalities in our study

Table 4 Association of knee pain stratified by knee synovial abnormalities on ultrasound and radiographic osteoarthritis status

\begin{tabular}{|c|c|c|c|c|}
\hline $\begin{array}{l}\text { Synovial abnormalities and ROA } \\
\text { status }\end{array}$ & $\begin{array}{l}\text { No. of patients with knee pain } \\
\text { (\%) }\end{array}$ & $\begin{array}{l}\text { Crude OR }(95 \% \\
\text { CI) }\end{array}$ & $\begin{array}{l}\text { Adjusted OR (95\% } \\
\text { CI) }^{\mathrm{a}}\end{array}$ & $\begin{array}{l}P \text { value of } \\
\text { interaction }\end{array}$ \\
\hline Synovial hypertrophy & & & & 0.004 \\
\hline Neither synovial hypertrophy nor ROA & $1013(20.6)$ & 1.00 (reference) & 1.00 (reference) & \\
\hline Synovial hypertrophy only & $86(25.4)$ & $1.31(1.00,1.71)$ & $1.46(1.10,1.93)$ & \\
\hline ROA only & $772(47.7)$ & $3.51(3.04,4.04)$ & $2.45(2.10,2.87)$ & \\
\hline Synovial hypertrophy and ROA & $313(65.8)$ & $7.40(5.86,9.34)$ & $5.51(4.27,7.11)$ & \\
\hline Joint effusion & & & & 0.067 \\
\hline Neither joint effusion nor ROA & $744(19.7)$ & 1.00 (reference) & 1.00 (reference) & \\
\hline Joint effusion only & $355(24.1)$ & $1.29(1.10,1.52)$ & $1.34(1.13,1.59)$ & \\
\hline ROA only & $560(47.8)$ & $3.74(3.17,4.40)$ & $2.62(2.18,3.14)$ & \\
\hline Joint effusion and ROA & $525(56.8)$ & $5.35(4.47,6.40)$ & $3.86(3.18,4.69)$ & \\
\hline Power Doppler signal & & & & 0.794 \\
\hline $\begin{array}{l}\text { Neither Power Doppler signal nor } \\
\text { ROA }\end{array}$ & $1075(20.7)$ & 1.00 (reference) & 1.00 (reference) & \\
\hline Power Doppler signal only & $24(45.3)$ & $3.18(1.81,5.58)$ & $3.12(1.70,5.73)$ & \\
\hline ROA only & $971(50.0)$ & $3.84(3.35,4.39)$ & $2.69(2.31,3.12)$ & \\
\hline Power Doppler signal and ROA & $114(74.0)$ & $10.94(7.34,16.30)$ & $8.34(5.44,12.80)$ & \\
\hline
\end{tabular}

$O R$ odds ratio, $\mathrm{Cl}$ confidence interval, $R O A$ radiographic osteoarthritis

${ }^{a}$ Adjusted for age, sex, BMI, smoking status, alcohol consumption, education level, and knee injury history 
was comparable with these previous studies, suggesting similar findings in diverse populations (China, USA, UK, and Italy). Several previous studies also reported higher prevalence of synovial hypertrophy and effusion in men than women $[20,21,33]$. This finding may be partly explained by the fact that men normally have thicker synovium and more synovial fluid than women [21]. The high prevalence of abnormal ultrasound values in this and previous general population samples suggest that, rather than using a fixed cut-off of $\geq 4 \mathrm{~mm}$ for "abnormal" synovial hypertrophy and effusion, different cutoffs for presence of hypertrophy and effusion, and for men and women, might be calculated from normal ranges and incorporated into future studies.

Previous studies have sought an association between ultrasound-detected synovial changes and knee pain, but results have been inconclusive [20, 28, 34-48]. Most studies were conducted in people with knee OA $[28,34-47]$ and were conditional on an intermediate variable (i.e., requirement of ROA), which may introduce selection bias (i.e., collider bias [49]) that dilutes the effect estimate. Our study provided empirical evidence that presence of synovial hypertrophy, effusion, and PDS all strongly associated both with presence and severity of knee pain, independent of potential confounders. We also demonstrated a positive association between synovial abnormalities and presence and severity of ROA. These results accord with previous findings [22, 48, 50], and reinforce that synovial changes are involved in knee OA.

Our study involved a large, general population-based sample $(n=3755)$ and had sufficient power to generate a representative estimate of prevalence of three synovial abnormalities in the general population, and to examine each of these features in relation to knee pain and ROA. Secondly, when examining the association between synovial abnormalities and knee pain, we compared the two knees within people who had knees discordant for presence of knee pain and pain severity. Being that within an individual all person-level factors that influence pain would contribute equally to both knees, this approach eliminated confounders between individuals and allowed determination of valid effect estimates of specific synovial abnormalities on knee pain. Thirdly, all ultrasound examinations were performed by a single experienced musculoskeletal sonographer, thus eliminating interobserver variability. Nevertheless, we assessed interobserver reliability with another expert musculoskeletal ultrasonographer and the results were excellent, providing external validation of the measures.

Our study has some limitations. First, participants were residents in rural areas of China with low prevalence of obesity (5.6\%); thus, caution must be taken when generalizing our results to urban, suburban, or obese populations. Second, we used EULAR recommended cut-offs for synovial abnormalities, which may not be generalizable to the Chinese population. Third, we were unable to confirm a diagnosis of rheumatoid arthritis based on the 1987 American College of Rheumatology (ACR) or 2010 American College of Rheumatology/European League Against Rheumatism (ACR/EULAR) criteria in the current study. Nevertheless, when subjects who self-reported rheumatoid arthritis with typical radiographic evidence or antirheumatoid therapy [51] were excluded, the results did not change materially (data not shown). Fourth, the associations between synovial hypertrophy and effusion, but not PDS, with knee pain were more pronounced among knees with ROA than those without ROA. We postulate that the low prevalence of PDS in the current study may have limited the study power when interaction of PDS and OA on knee pain was assessed. Fifth, this is a cross-sectional study, so we cannot confirm temporal association and causality between synovial abnormalities, ROA, and pain. The association identified between synovial features and ROA does not necessarily mean that synovial features are the causes or consequences of the ROA. In addition, the associations between synovial abnormalities and knee pain remained similar after further adjusting for knee ROA (data not shown), indicating that these associations may be independent of ROA. However, since previous studies report that synovial abnormalities increased the risk of incident knee ROA [52, 53], adjusting for ROA may be akin to adjusting for an intermediate variable between synovial abnormalities and knee pain, leading to a biased effect estimate [49].

Since ultrasound enables real-time noninvasive imaging of synovial abnormalities at low cost, knee ultrasound especially for initial assessment of knee synovial abnormalities could be encouraged. In addition, knee synovial abnormalities have been found to associate with knee pain and ROA. Thus, the high prevalence of synovial abnormalities in the general population in our study suggests a potentially higher burden of knee pain and $\mathrm{OA}$ than previously thought. However, whether these synovial changes are beneficial or damaging remains unclear. They may reflect the joint's attempted repair response to insult, which is characterized by increased physiological/pathological activity and hyperplasia of joint tissues. Indeed, a modest degree of inflammation as part of repair, rather than aggressive synovitis, is supported by the lower prevalence of PDS. Furthermore, approximately half of the participants with knee pain but no ROA had synovial abnormalities. However, longitudinal studies are needed to verify whether ultrasound-detected synovial abnormalities could predict incident knee ROA. Considering that synovial 
abnormalities present a potentially modifiable pathological process [9], additional imaging with ultrasound may be of value in clinical practice.

\section{Conclusions}

In conclusion, knee synovial hypertrophy and effusion are more common and increase with age, affecting men more than women. All three ultrasound-detected synovial abnormalities associate both with knee pain and ROA, and knee synovial hypertrophy or effusion and ROA may interact to increase the risk of knee pain.

\section{Abbreviations}

ROA: Radiographic osteoarthritis; PDS: Power Doppler signal; aORs: Adjusted odds ratios; Cl: Confidence interval; OA: Osteoarthritis; MRI: Magnetic resonance imaging; CE-MRI: Contrast-enhanced MRI; PD: Power Doppler; XO Study: Xiangya Osteoarthritis Study; OMERACT: Outcome Measures in Rheumatology; EULAR: European League Against Rheumatism; ICC: Intra-class correlation coefficient; WOMAC: Western Ontario and McMaster Universities Osteoarthritis Index; TF: Tibiofemoral; PF: Patellofemoral; KL: KellgrenLawrence; BMI: Body mass index; SD: Standard deviation; OR: Odds ratio

\section{Supplementary Information}

The online version contains supplementary material available at https:/doi. org/10.1186/s13075-021-02539-2.

\section{Additional file 1: Supplemental Figure 1. Recruitment and} enrollment of study participants in Xiangya Osteoarthritis Study (XO Study). Supplemental Figure 2. Longitudinal ultrasonographic scan of suprapatellar recess (B mode). SH, synovial hypertrophy; $\mathrm{E}$, joint effusion Supplemental Figure 3. Longitudinal ultrasonographic scan of suprapatellar recess (Power Doppler mode). Power Doppler signal (PDS) at synovial membrane was scored using a semi-quantitative grading system, from 0 to 3 ( $0=$ absent, $1=$ mild, $2=$ moderate, $3=$ marked or severe). (A) grade 0 , (B) grade $1,(C)$ grade 2 . We did not detected grade 3 PDS in knee joints of participants of our study. Supplemental Figure 4. Bilateral weight-bearing posterior-anterior tibio-femoral radiographs, assessed according to Kellgren and Lawrence (KL) criteria: (A) grade 0, (B) grade 1, (C) grade 2, (D) grade 3 and (E) grade 4. Supplemental Figure 5. Skyline views of patellofemoral radiographs, assessed according to Kellgren and Lawrence (KL) criteria: (A) grade 0 , (B) grade 1, (C) grade 2, (D) grade 3 and (E) grade 4. Supplemental Table 1. The intra- and inter-rater reliability for ultrasound-detected synovial abnormalities and KellgrenLawrence grade of knee radiography. Supplemental Table 2. Prevalence of knee synovial abnormalities on ultrasound among middle-aged and elderly persons, according to age group and sex. Supplemental Table 3. Association of knee synovial abnormalities on ultrasound and knee pain. Supplemental Table 4. Association of knee synovial abnormalities on ultrasound and knee pain among people with two knees discordant for knee pain. Supplemental Table 5. Association of knee synovial abnormalities on ultrasound and knee radiographic osteoarthritis. Supplemental Table 6. Association of knee pain stratified by knee synovial abnormalities on ultrasound and radiographic osteoarthritis status among people with two knees discordant for knee pain.

\section{Acknowledgements}

The authors acknowledge Piran Aliabadi (Department of Radiology, Brigham and Women's Hospital, Harvard Medical School), Sally A. Doherty (Rheumatology, Orthopaedics and Dermatology, University of Nottingham), Richard Wakefield (Leeds Institute of Rheumatic and Musculoskeletal Medicine, Chapel Allerton Hospital, University of Leeds), Yilun Wang, Xiaoxiao Li, Dongxing Xie, Jing Wu, Bei Xu, Jian Tian, Yuqing Wang, Zhenglei Zhu, Fan Wu, Ke He, Haochen Wang, Hongyi He, Ning Wang, Ziying Wu, Hui Li, Xiang Ding, Bin Zhou, Ye Yang, Ruijun Bai, Zhichen Liu, Kun Li, Junyu Zhu, Xinjia Deng, Xing Huang, Manli Chen, Li Zhang, Ying Pan, Zikun Xie, and Renpeng
Fang (Xiangya Hospital, Central South University) for their contribution to this study.

\section{Patient and public involvement}

No patients were involved in setting the research question or the outcome measures, nor were they involved in developing plans for design or implementation of the study. No patients were asked to advise on interpretation or writing up of results. Dissemination of the findings to participants is not possible owing to the use of an anonymised dataset.

\section{Transparency}

The lead author affirms that the manuscript is an honest, accurate, and transparent account of the study being reported; that no important aspects of the study have been omitted; and that any discrepancies from the study as planned have been explained.

\section{Authors' contributions}

$G L$ and $C Z$ are joint corresponding authors. All authors have read, provided critical feedback on intellectual content, and approved the final manuscript. $G L$ and $C Z$ conceived the study. GL, CZ, WZ, MD, YZ, and JW designed the study. TJ performed the ultrasound examination and assessment. TJ, AS, GSF, $A D O, S A G$, and PC standardized the ultrasound examination and assessment according to EULAR and OMERACT atlas. TY and JL contributed to the collection of clinical data. TJ and $\mathrm{MH}$ did the reliability test of ultrasound assessment. TY performed the Kellgren-Lawrence (KL) scoring of knee joints. $J W$ and $Z Y$ analyzed the data. TJ and TY drafted the manuscript. GL, CZ, WZ, $M D$, and $Y Z$ revised the manuscript.

\section{Funding}

This work was supported by the National Key R\&D Program of China (2018YFB1 105700), the National Natural Science Foundation of China (81772413, 81930071, 81902265, 82072502), the Project Program of National Clinical Research Center for Geriatric Disorders (Xiangya Hospital, 2020LNJJ03), the Key Research and Development Program of Hunan Province (2018SK2070, 2018SK2072, 2018SK2074), and the Science and Technology Program of Hunan Province (2019RS2010). The funding source had no role in the design and conduct of the study; collection, management, analysis, and interpretation of the data; preparation, review, or approval of the manuscript; and the decision to submit the manuscript for publication.

\section{Availability of data and materials}

The datasets analyzed during the current study are available from the corresponding authors on reasonable request.

\section{Declarations}

Ethics approval and consent to participate

This study received approval from the medical ethical committee at Xiangya Hospital (201510506), with written informed consent obtained from all participants.

\section{Consent for publication}

Not applicable.

\section{Competing interests}

The authors have no conflicts of interest to declare.

\section{Author details}

'Department of Orthopaedics, Xiangya Hospital, Central South University, 87 Xiangya Road, Changsha 410008, Hunan, China. ${ }^{2}$ Department of Ultrasonography, Xiangya Hospital, Central South University, Changsha, China. ${ }^{3}$ Division of Rheumatology, Orthopaedics and Dermatology, University of Nottingham, Nottingham, UK. ${ }^{4}$ Pain Centre Versus Arthritis UK, Nottingham, UK. ${ }^{5}$ Health Management Center, Xiangya Hospital, Central South University, Changsha, China. ${ }^{6}$ Division of Rheumatology, Allergy, and Immunology, Department of Medicine, Massachusetts General Hospital, Harvard Medical School, Boston, USA. ${ }^{7}$ The Mongan Institute, Massachusetts General Hospital, Harvard Medical School, Boston, USA. ${ }^{8}$ Hunan Key Laboratory of Joint Degeneration and Injury, Xiangya Hospital, Central South University, Changsha, China. ${ }^{9}$ Musculoskeletal Research Unit, Bristol Medical 
School, University of Bristol, Bristol, UK. ${ }^{10}$ School of Health Sciences, University of Nottingham, Nottingham, UK. ${ }^{11}$ NIHR Nottingham Biomedical Research Centre, School of Medicine, University of Nottingham, Nottingham, UK. ${ }^{12}$ Population Health Sciences, Bristol Medical School, University of Bristol, Bristol, UK. ${ }^{13}$ Department of Rheumatology, Nottingham University Hospitals NHS Trust, Nottingham, UK. ${ }^{14}$ National Clinical Research Center for Geriatric Disorders, Xiangya Hospital, Central South University, Changsha, China.

\section{Received: 29 January 2021 Accepted: 19 May 2021}

Published online: 02 June 2021

\section{References}

1. Peat G, McCarney R, Croft P. Knee pain and osteoarthritis in older adults: a review of community burden and current use of primary health care. Ann Rheum Dis. 2001;60(2):91-7. https://doi.org/10.1136/ard.60.2.91.

2. Sarmanova A, Fernandes GS, Richardson H, Valdes AM, Walsh DA, Zhang W, et al. Contribution of central and peripheral risk factors to prevalence, incidence and progression of knee pain: a community-based cohort study. Osteoarthr Cartil. 2018;26(11):1461-73. https://doi.org/10.1016/j.joca.2018.07. 013.

3. Jordan J, Luta G, Renner J, Dragomir A, Hochberg M, Fryer J. Knee pain and knee osteoarthritis severity in self-reported task specific disability: the Johnston County Osteoarthritis Project. J Rheumatol. 1997;24(7):1344-9.

4. Hall MC, Mockett SP, Doherty M. Relative impact of radiographic osteoarthritis and pain on quadriceps strength, proprioception, static postural sway and lower limb function. Ann Rheum Dis. 2006;65(7):865-70. https://doi.org/10.1136/ard.2005.043653.

5. Wilkie R, Peat G, Thomas E, Croft P. Factors associated with restricted mobility outside the home in community-dwelling adults ages fifty years and older with knee pain: an example of use of the International Classification of Functioning to investigate participation restriction. Arthritis Rheum. 2007;57(8):1381-9. https://doi.org/10.1002/art.23083.

6. Bindawas SM, Vennu V, Al Snih S. Differences in health-related quality of life among subjects with frequent bilateral or unilateral knee pain: data from the Osteoarthritis Initiative study. J Orthop Sports Phys Ther. 2015;45(2):12836. https://doi.org/10.2519/jospt.2015.5123.

7. Kluzek S, Sanchez-Santos MT, Leyland KM, Judge A, Spector TD, Hart D, et al. Painful knee but not hand osteoarthritis is an independent predictor of mortality over 23 years follow-up of a population-based cohort of middle-aged women. Ann Rheum Dis. 2016;75(10):1749-56. https://doi. org/10.1136/annrheumdis-2015-208056.

8. Baker K, Grainger A, Niu J, Clancy M, Guermazi A, Crema M, et al. Relation of synovitis to knee pain using contrast-enhanced MRIs. Ann Rheum Dis. 2010; 69(10):1779-83. https://doi.org/10.1136/ard.2009.121426.

9. Conaghan PG, Cook AD, Hamilton JA, Tak PP. Therapeutic options for targeting inflammatory osteoarthritis pain. Nat Rev Rheumatol. 2019;15(6): 355-63. https://doi.org/10.1038/s41584-019-0221-y.

10. Guermazi A, Niu J, Hayashi D, Roemer FW, Englund M, Neogi T, et al. Prevalence of abnormalities in knees detected by MRI in adults without knee osteoarthritis: population based observational study (Framingham Osteoarthritis Study). BMJ. 2012;345(aug29 1):e5339. https://doi.org/10.1136/ bmj.e5339.

11. Wang X, Blizzard L, Halliday A, Han W, Jin X, Cicuttini F, et al. Association between MRI-detected knee joint regional effusion-synovitis and structural changes in older adults: a cohort study. Ann Rheum Dis. 2016;75(3):519-25. https://doi.org/10.1136/annrheumdis-2014-206676.

12. Chrysochou C, Power A, Shurrab AE, Husain S, Moser S, Lay J, et al. Low risk for nephrogenic systemic fibrosis in nondialysis patients who have chronic kidney disease and are investigated with gadolinium-enhanced magnetic resonance imaging. Clin J Am Soc Nephrol. 2010;5(3):484-9. https://doi. org/10.2215/CJN.06580909.

13. Conaghan P, D'Agostino MA, Ravaud P, Baron G, Le Bars M, Grassi W, et al. EULAR report on the use of ultrasonography in painful knee osteoarthritis. Part 2: exploring decision rules for clinical utility. Ann Rheum Dis. 2005; 64(12):1710-4. https://doi.org/10.1136/ard.2005.038026.

14. Bruyn GA, Naredo E, Damjanov N, Bachta A, Baudoin P, Hammer HB, et al. An OMERACT reliability exercise of inflammatory and structural abnormalities in patients with knee osteoarthritis using ultrasound assessment. Ann Rheum Dis. 2016;75(5):842-6. https://doi.org/10.1136/a nnrheumdis-2014-206774.
15. Kane D, Balint PV, Sturrock RD. Ultrasonography is superior to clinical examination in the detection and localization of knee joint effusion in rheumatoid arthritis. J Rheumatol. 2003;30(5):966-71.

16. Bao Z, Zhao Y, Chen S, Chen X, Xu X, Wei L, et al. Ultrasound versus contrast-enhanced magnetic resonance imaging for subclinical synovitis and tenosynovitis: a diagnostic performance study. Clinics (Sao Paulo). 2020; 75:e1500. https://doi.org/10.6061/clinics/2020/e1500.

17. Naredo E, Bonilla G, Gamero F, Uson J, Carmona L, Laffon A. Assessment of inflammatory activity in rheumatoid arthritis: a comparative study of clinical evaluation with grey scale and power Doppler ultrasonography. Ann Rheum Dis. 2005;64(3):375-81. https://doi.org/10.1136/ard.2004.023929.

18. Sarmanova A, Hall M, Moses J, Doherty M, Zhang W. Synovial changes detected by ultrasound in people with knee osteoarthritis - a meta-analysis of observational studies. Osteoarthr Cartil. 2016;24(8):1376-83. https://doi. org/10.1016/j.joca.2016.03.004.

19. Abraham AM, Pearce MS, Mann KD, Francis RM, Birrell F. Population prevalence of ultrasound features of osteoarthritis in the hand, knee and hip at age 63 years: the Newcastle thousand families birth cohort. BMC Musculoskelet Disord. 2014;15(1):162. https://doi.org/10.1186/1471-2474-15-1 62

20. D'Agostino MA, lagnocco A, Aegerter P, Kleyer A, Zwerina J, Perricone C, et al. Does subclinical inflammation contribute to impairment of function of knee joints in aged individuals? High prevalence of ultrasound inflammatory findings. Rheumatology (Oxford). 2015;54(9):1622-9. https://doi.org/10.1093/ rheumatology/kev032.

21. Sarmanova A, Hall M, Fernandes GS, Valdes AM, Walsh DA, Doherty M, et al. Thresholds of ultrasound synovial abnormalities for knee osteoarthritis - a cross sectional study in the general population. Osteoarthr Cartil. 2019;27(3): 435-43. https://doi.org/10.1016/j.joca.2018.09.018.

22. Yerich NV, Alvarez C, Schwartz TA, Savage-Guin S, Renner JB, Bakewell CJ, et al. A standardized, pragmatic approach to knee ultrasound for clinical research in osteoarthritis: The Johnston County Osteoarthritis Project. ACR Open Rheumatol. 2020;2(7):438-48. https://doi.org/10.1002/acr2.11159.

23. Claessens AA, Schouten JS, van den Ouweland FA, Valkenburg HA. Do clinical findings associate with radiographic osteoarthritis of the knee? Ann Rheum Dis. 1990:49(10):771-4. https://doi.org/10.1136/ard.49.10.771.

24. Jenkinson CM, Doherty M, Avery AJ, Read A, Taylor MA, Sach TH, et al. Effects of dietary intervention and quadriceps strengthening exercises on pain and function in overweight people with knee pain: randomised controlled trial. BMJ. 2009;339(aug18 2):b3170. https://doi.org/10.1136/bmj. b3170.

25. Zeng C, Wei J, Terkeltaub R, Yang T, Choi HK, Wang YL, et al. Dose-response relationship between lower serum magnesium level and higher prevalence of knee chondrocalcinosis. Arthritis Res Ther. 2017;19(1):236. https://doi. org/10.1186/s13075-017-1450-6.

26. Wei J, Zhang C, Zhang Y, Zhang W, Doherty M, Yang T, et al. Association between gut microbiota and symptomatic hand osteoarthritis: data from the Xiangya Osteoarthritis Study. Arthritis Rheum. 2021. https://doi.org/10.1 002/art.41729.

27. Wakefield RJ, Balint PV, Szkudlarek M, Filippucci E, Backhaus M, D'Agostino MA, et al. Musculoskeletal ultrasound including definitions for ultrasonographic pathology. J Rheumatol. 2005;32(12):2485-7.

28. D'Agostino MA, Conaghan P, Le Bars M, Baron G, Grassi W, Martin-Mola E, et al. EULAR report on the use of ultrasonography in painful knee osteoarthritis. Part 1: prevalence of inflammation in osteoarthritis. Ann Rheum Dis. 2005;64(12):1703-9. https://doi.org/10.1136/ard.2005.037994.

29. lagnocco A, Meenagh G, Riente L, Filippucci E, Delle Sedie A, Scire CA, et al. Ultrasound imaging for the rheumatologist XXIX. Sonographic assessment of the knee in patients with osteoarthritis. Clin Exp Rheumatol. 2010;28(5): 643-6.

30. Bellamy N, Buchanan WW, Goldsmith CH, Campbell J, Stitt LW. Validation study of WOMAC: a health status instrument for measuring clinically important patient relevant outcomes to antirheumatic drug therapy in patients with osteoarthritis of the hip or knee. J Rheumatol. 1988;15(12): 1833-40.

31. Neogi T, Felson D, Niu J, Nevitt M, Lewis CE, Aliabadi P, et al. Association between radiographic features of knee osteoarthritis and pain: results from two cohort studies. BMJ. 2009;339(aug21 1):b2844. https://doi.org/10.1136/ bmj.b2844.

32. Brown LD, Cai TT, DasGupta A. Interval estimation for a binomial proportion. Stat Sci. 2001;16(2):101-33. 
33. Machado FS, Natour J, Takahashi RD, de Buosi AL, Furtado RN. Sonographic assessment of healthy peripheral joints: evaluation according to demographic parameters. J Ultrasound Med. 2014;33(12):2087-98. https:// doi.org/10.7863/ultra.33.12.2087.

34. Chan KK, Sit RW, Wu RW, Ngai AH. Clinical, radiological and ultrasonographic findings related to knee pain in osteoarthritis. PLoS One. 2014;9(3):e92901. https://doi.org/10.1371/journal.pone.0092901.

35. Abbasi B, Pezeshki-Rad M, Akhavan R, Sahebari M. Association between clinical and sonographic synovitis in patients with painful knee osteoarthritis. Int J Rheum Dis. 2017;20(5):561-6. https://doi.org/10.1111/1 756-185X.12834.

36. Wu PT, Shao CJ, Wu KC, Wu TT, Chern TC, Kuo LC, et al. Pain in patients with equal radiographic grades of osteoarthritis in both knees: the value of gray scale ultrasound. Osteoarthr Cartil. 2012;20(12):1507-13. https://doi. org/10.1016/j.joca.2012.08.021.

37. Chiba D, Tsuda E, Maeda S, Sasaki E, Takahashi I, Nakaji S, et al. Evaluation of a quantitative measurement of suprapatellar effusion by ultrasonography and its association with symptoms of radiographic knee osteoarthritis: a cross-sectional observational study. Arthritis Res Ther. 2016;18(1):181. https:// doi.org/10.1186/s13075-016-1078-y.

38. Abd El Monaem SM, Hashaad NI, Ibrahim NH. Correlations between ultrasonographic findings, clinical scores, and depression in patients with knee osteoarthritis. Eur J Rheumatol. 2017;4(3):205-9. https://doi.org/10.51 52/eurjrheum.2017.160097.

39. Mosalem DM, Alghunaim SM, Shehab DK, Bager AB, Alfeeli AK, Ahmed MM. Soft tissue pathology detected by ultrasound seem to be risk factors for painful flare in osteoarthritic knee. Open Access Maced J Med Sci. 2018;6(9): 1599-605. https://doi.org/10.3889/oamjms.2018.237.

40. Razek AA, El-Basyouni SR. Ultrasound of knee osteoarthritis: interobserver agreement and correlation with Western Ontario and McMaster Universities Osteoarthritis. Clin Rheumatol. 2016;35(4):997-1001. https://doi.org/10.1007/ s10067-015-2990-2.

41. Oo WM, Linklater JM, Bennell KL, Yu S, Fu K, Wang X, et al. Superb microvascular imaging in low-grade inflammation of knee osteoarthritis compared with power doppler: clinical, radiographic and MRI relationship. Ultrasound Med Biol. 2020;46(3):566-74. https://doi.org/10.1016/j.ultra smedbio.2019.11.017.

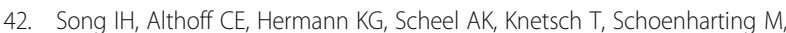
et al. Knee osteoarthritis. Efficacy of a new method of contrast-enhanced musculoskeletal ultrasonography in detection of synovitis in patients with knee osteoarthritis in comparison with magnetic resonance imaging. Ann Rheum Dis. 2008;67(1):19-25. https://doi.org/10.1136/ard.2006.067462.

43. Bevers K, Bijlsma JW, Vriezekolk JE, van den Ende $\mathrm{CH}$, den Broeder AA. Ultrasonographic features in symptomatic osteoarthritis of the knee and relation with pain. Rheumatology (Oxford). 2014;53(9):1625-9. https://doi. org/10.1093/rheumatology/keu030.

44. Serban O, Porojan M, Deac M, Cozma F, Solomon C, Lenghel M, et al. Pain in bilateral knee osteoarthritis - correlations between clinical examination, radiological, and ultrasonographical findings. Med Ultrason. 2016;18(3):31825. https://doi.org/10.11152/mu.2013.2066.183.pin.

45. Bernardo-Bueno MM, Gonzalez-Suarez CB, Malvar AK, Cua R, Feliciano D, Tan-Sales BG, et al. Stratifying minimal versus severe pain in knee osteoarthritis using a musculoskeletal ultrasound protocol. J Ultrasound Med. 2019;38(6):1411-23. https://doi.org/10.1002/jum.14819.

46. Kandemirli GC, Basaran M, Kandemirli S, Inceoglu LA. Assessment of knee osteoarthritis by ultrasonography and its association with knee pain. J Back Musculoskelet Rehabil. 2020;33(4):711-17. https://doi.org/10.3233/BMR-191 504.

47. Kristoffersen H, Torp-Pedersen S, Terslev L, Qvistgaard E, Holm CC, Ellegaard $K$, et al. Indications of inflammation visualized by ultrasound in osteoarthritis of the knee. Acta Radiol. 2006;47(3):281-6. https://doi.org/10.1080/02841 850600551508.

48. Sarmanova A, Hall M, Fernandes GS, Bhattacharya A, Valdes AM, Walsh DA, et al. Association between ultrasound-detected synovitis and knee pain: a population-based case-control study with both cross-sectional and followup data. Arthritis Res Ther. 2017;19(1):281. https://doi.org/10.1186/s13075-01 7-1486-7.

49. Choi HK, Nguyen US, Niu J, Danaei G, Zhang Y. Selection bias in rheumatic disease research. Nat Rev Rheumatol. 2014;10(7):403-12. https://doi.org/10.1 038/nrrheum.2014.36.
50. Hall M, Doherty S, Courtney P, Latief K, Zhang W, Doherty M. Synovial pathology detected on ultrasound correlates with the severity of radiographic knee osteoarthritis more than with symptoms. Osteoarthr Cartil. 2014;22(10):1627-33. https://doi.org/10.1016/j.joca.2014.05.025.

51. Zhang $Y$, Terkeltaub R, Nevitt M, Xu L, Neogi T, Aliabadi P, et al. Lower prevalence of chondrocalcinosis in Chinese subjects in Beijing than in white subjects in the United States: the Beijing Osteoarthritis Study. Arthritis Rheum. 2006;54(11):3508-12. https://doi.org/10.1002/art.22189.

52. Roemer FW, Kwoh CK, Hannon MJ, Hunter DJ, Eckstein F, Fujii T, et al. What comes first? Multitissue involvement leading to radiographic osteoarthritis: magnetic resonance imaging-based trajectory analysis over four years in the osteoarthritis initiative. Arthritis Rheum. 2015;67(8):2085-96. https://doi.org/1 0.1002 /art.39176.

53. Atukorala I, Kwoh CK, Guermazi A, Roemer FW, Boudreau RM, Hannon MJ, et al. Synovitis in knee osteoarthritis: a precursor of disease? Ann Rheum Dis. 2016;75(2):390-5. https://doi.org/10.1136/annrheumdis-2014-205894.

\section{Publisher's Note}

Springer Nature remains neutral with regard to jurisdictional claims in published maps and institutional affiliations.

\section{Ready to submit your research? Choose BMC and benefit from:}

- fast, convenient online submission

- thorough peer review by experienced researchers in your field

- rapid publication on acceptance

- support for research data, including large and complex data types

- gold Open Access which fosters wider collaboration and increased citations

- maximum visibility for your research: over $100 \mathrm{M}$ website views per year

At $\mathrm{BMC}$, research is always in progress.

Learn more biomedcentral.com/submissions 